Article

\title{
Effects of Ultrasound Treatment on Extraction and Rheological Properties of Polysaccharides from Auricularia Cornea var. Li.
}

\author{
Yinping Wang ${ }^{1}$, Cuina Wang ${ }^{1}$ and Mingruo Guo ${ }^{2,3, *}$ \\ 1 College of Food Science and Engineering, Jilin University, Changchun, Jilin 130062, China; \\ ypwang0812@163.com (Y.W.); wangcuina@jlu.edu.cn (C.W.) \\ 2 Department of Nutrition and Food Science, College of Agriculture and Life Sciences, University of Vermont, \\ Burlington, VT 05405, USA \\ 3 Department of Food Science, Northeast Agricultural University, Harbin, Heilongjiang 150030, China \\ * Correspondence: mguo@uvm.edu; Tel.: +1-(802)-656-8168; Fax: +1-802-656-0001
}

Received: 3 February 2019; Accepted: 28 February 2019; Published: 7 March 2019

\begin{abstract}
Auricularia cornea var. Li. is an edible fungi and polysaccharides in Auricularia cornea var. Li. may have bioactive activities. Polysaccharides from Auricularia cornea var. Li. (ACP) was extracted using ultrasound-assisted extraction (UAE) method and compared with hot water extraction (HWE) for extraction yield, extraction rate, purity of polysaccharides, microstructure of residues after extraction, preliminary structure and rheological properties of polysaccharides. Optimum conditions for UAE (particle size of 150-200 mesh, water to raw material ratio of 70:1, extraction temperature at $70{ }^{\circ} \mathrm{C}$ for $40 \mathrm{~min}$, ultrasonic amplitude of $40 \%$ ) and $\mathrm{HWE}$ (particle size of 150-200 mesh, water to raw material ratio of $60: 1$, extraction temperature at $90{ }^{\circ} \mathrm{C}$ for $3.0 \mathrm{~h}$ ) were obtained via single-factor experiment. Under optimum conditions, extraction yield of polysaccharides by UAE was $30.99 \pm 1.93 \%$ which showed no significant difference with that by HWE $(30.35 \pm 1.67 \%)$ $(P>0.05)$. Extraction rate $(29.29 \pm 1.41 \%)$ and purity $(88.62 \pm 2.80 \%)$ of polysaccharides by UAE were higher than those by HWE (extraction rate of $24.95 \pm 2.78 \%$ and purity of $75.33 \pm 6.15 \%)(P<0.05)$. Scanning Electron Microscopy (SEM) images of residues by UAE showed more broken cells than those by HWE. Fourier Transform Infrared (FTIR) spectra showed that the dialyzed ACP extracted by HWE and UAE (DACP-HWE and DACP-UAE) had similar characteristic absorption peaks of polysaccharides. Both DACP-HWE and DACP-UAE solutions showed typical shear thinning and temperature-independent behaviors $\left(25-90^{\circ} \mathrm{C}\right)$ and UAE resulted in polysaccharides with remarkably lower viscosity in comparison with HWE. DACP-UAE solutions exhibited more liquid-like state while DACP-HWE solutions solid-like system. Data indicated that ultrasound treatment may be a useful means for extraction of polysaccharides from Auricularia cornea var. Li.
\end{abstract}

Keywords: Auricularia cornea var. Li.; polysaccharides; ultrasound-assisted extraction; structure; rheological properties

\section{Introduction}

Edible fungi contain various bioactive components including polysaccharides, polyphenol, protein and vitamins [1]. Especially, edible fungi polysaccharides have attracted attention due to its potentially medicinal values, such as anti-oxidative [2], antitumor [3,4], anti-proliferation [5] and hypoglycemic activities [6]. In recent years, novel techniques including enzyme-assisted extraction [7], microwave-assisted extraction [8,9] and ultrasound-assisted extraction [10] have been applied for extraction of polysaccharides from edible fungi. Among all the methods, enzyme-assisted extraction has advantages being environmentally friendly and high efficient [11], however, the enzyme activity 
could be easily influenced by several factors [12]. Microwave-assisted extraction could enhance extraction efficiency with less time consumption [8]. It may have the disadvantage of inhomogeneous heating [13]. Ultrasound-assisted extraction (UAE) is a popular means due to quick and high efficiency $[14,15]$. It could improve the yield of polysaccharides by disrupting the cell walls, reducing the particle size and enhancing contact between solvents and targeted compounds due to the acoustic cavitation effect [16].

Studies on rheological properties of polysaccharides may provide useful information for their application as potential thickeners and stabilizers in food industry [17,18]. Bao et al. [19] reported that water-soluble polysaccharides from Auricularia auricular-judae exhibited desirable functional properties including high viscosity with shear-thinning behavior and forming thermal stable gels ability, which were useful for application in food industry. Ma et al. [17] investigated effects of different concentration, temperature and $\mathrm{pH}$ on rheological properties of polysaccharides from Dioscorea opposite Thunb, which contributed to the function and applications of natural thickeners in food industry.

Previous studies showed that rheological properties of polysaccharides could be affected by ultrasound treatment due to reduction of the molecular weight of polysaccharides [20]. Li et al. [21] reported that high intensity ultrasound reduced average molecular weight, particle size of konjac glucomannan aggregates without significant structural destruction and changed the rheological properties including the decrease of storage modulus $\left(G^{\prime}\right)$ and loss modulus $\left(G^{\prime \prime}\right)$ and the increase in phase angle. Zhong et al. [20] investigated molecular weight degradation of schizophyllan under ultrasonic treatment and showed that the reduction of viscosity and elastic behavior of polysaccharides may be related to its lower molecular weight after ultrasonic treatment. Seshadri et al. [22] studied the effect of high intensity ultrasound processing on rheological properties of high-methoxyl pectin dispersions and showed that cavitation effect from ultrasound induced the reduction in average molecular weight and changed the flow behavior of pectin, which had important implications for future applications of food hydrocolloids in food industry.

Edible fungi are regarded as a valuable source of nutritional and bioactive ingredients and have been used in dietary and medicinal applications for thousands of years [1,23]. Auricularia cornea var. Li. ("Yu Mu Er" in Chinese), a white-body edible fungi, is a variant of Auricularia cornea species [24]. It is rich in bioactive compounds such as dietary fiber and polysaccharides and has been cultivated and commercialized in China [25].

The objectives of this study were to extract polysaccharides from Auricularia cornea var. Li. using $\mathrm{UAE}$ and compared with hot water extraction (HWE) in terms of extraction yield, extraction rate, purity of polysaccharides, microstructure of residues after extraction. The optimum conditions for both extraction methods were obtained by single-factor experiment. The preliminary structure and rheological properties of polysaccharides extracted by HWE and UAE under the optimum conditions were also investigated.

\section{Results and Discussion}

\subsection{Effects of Single-Factor by Ultrasound-assisted Extraction on Extraction Yield and Extraction Rate of Polysaccharides from Auricularia cornea var. Li.}

Effects of 5 factors (particle size, water to raw material ratio, extraction temperature, extraction time, ultrasonic amplitude) by UAE on extraction yield and extraction rate of polysaccharides from Auricularia cornea var. Li. were evaluated and shown in Figure 1A-E. 

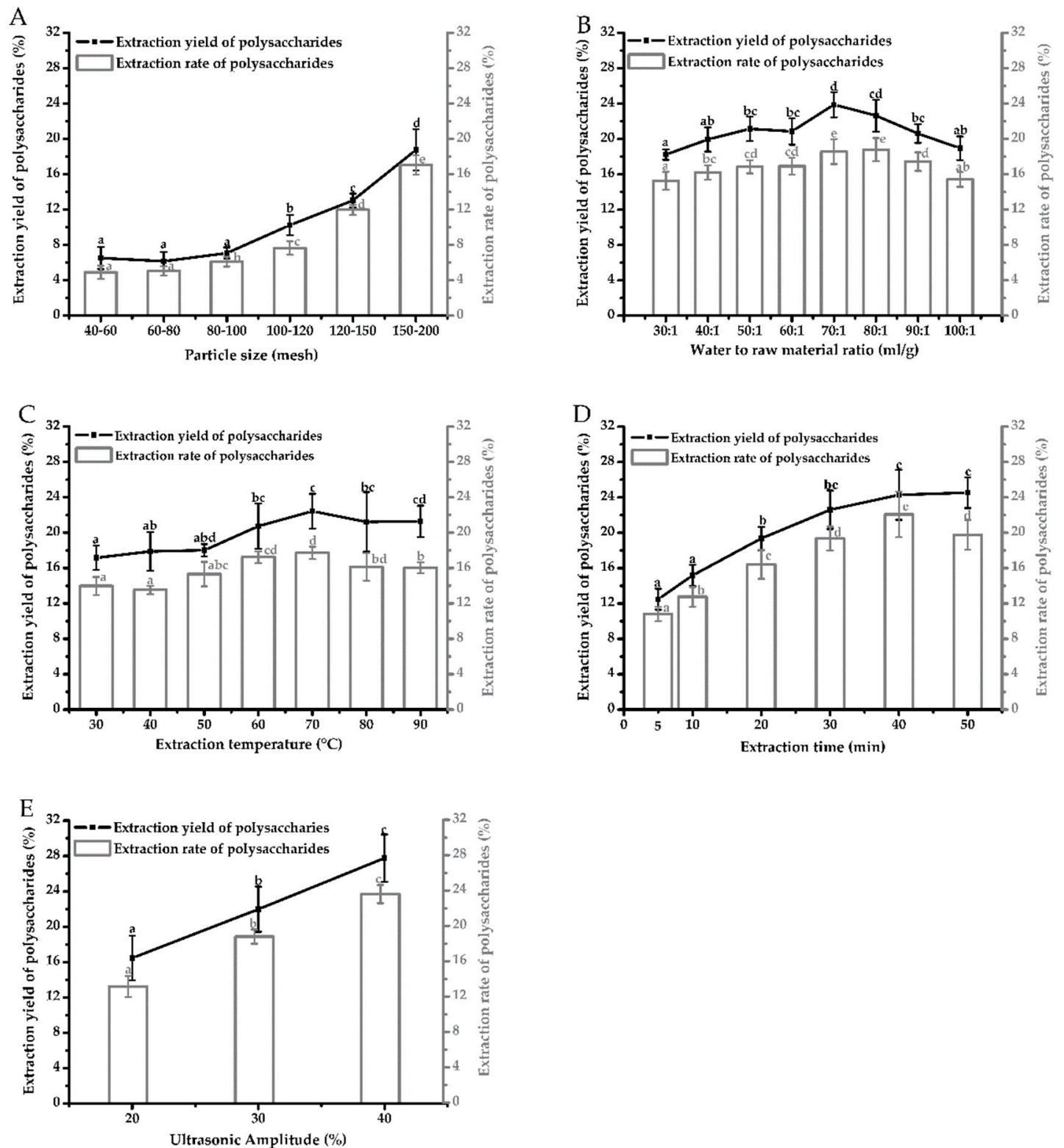

Figure 1. Effects of single-factor (A) particle size (B) water to raw material ratio (C) extraction temperature (D) extraction time (E) ultrasonic amplitude by ultrasound-assisted extraction (UAE) on extraction yield and extraction rate of polysaccharides from Auricularia cornea var. Li. Values with different letters are significantly different $(P<0.05)$ for extraction yield and extraction rate of polysaccharides.

Particle size was an important factor which can affect the extraction yield and extraction rate of polysaccharides [26]. Effects of particle size (40-60, 60-80, 80-100, 100-120, 120-150, 150-200 mesh) on extraction yield and extraction rate were evaluated at constant conditions of water to raw material ratio of $60: 1(\mathrm{~mL} / \mathrm{g})$, extraction temperature of $60^{\circ} \mathrm{C}$, extraction time of $20 \mathrm{~min}$, ultrasonic amplitude of $30 \%$. As shown in Figure 1A, no significant changes were found in extraction yield and extraction rate when particle size decreased from 40-60 to 60-80 mesh $(P>0.05)$. Notably, both extraction yield and extraction rate of polysaccharides increased significantly as particle size decreased from 80-100 to 150-200 mesh $(P<0.05)$. This indicated that more polysaccharides were transported from interior of particles to the solvent. Smaller particle sizes in certain range would result in high extraction efficiency due to a smaller resistance and shorter path to the polysaccharides diffusion between the raw material and solution [26]. However, some studies also reported that promotion of extraction 
yield may be impeded due to mass transfer resistance started to become larger when particle size continually reduced [27]. Powders at particle size of 150-200 mesh showed the highest extraction yield $(18.77 \pm 2.34 \%)$ and extraction rate $(17.07 \pm 1.10 \%)$ among all samples. Thus, $150-200$ mesh was selected as the optimum particle size.

Water to raw material ratio in UAE was set at 30:1, 40:1, 50:1, 60:1, 70:1, 80:1, 90:1, 100:1 (mL/g) and other extraction conditions were as following: particle size of 150-200 mesh, extraction temperature of $60{ }^{\circ} \mathrm{C}$, extraction time of $20 \mathrm{~min}$, ultrasonic amplitude of $30 \%$. As shown in Figure 1B, extraction yield and extraction rate of polysaccharides increased when water to raw material ratio increased from 30:1 to 70:1 $(P<0.05)$, then decreased rapidly with further increase from 80:1 to 100:1 $(P<0.05)$. Samples at ratio of 70:1 and 80:1 showed larger extraction yield and extraction rate $(P<0.05)$. Increasing the water to material ratio may improve the diffusion rate between the interior of raw material and the exterior solvent and enhanced the dissolution of polysaccharides [28,29]. However, too much solvent may prolong the distance of diffusion which may cause further loss of polysaccharides [29,30]. Water to raw material ratio of $70: 1(\mathrm{~mL} / \mathrm{g})$ with relatively high extraction yield $(23.88 \pm 1.43 \%)$ and extraction rate $(18.58 \pm 1.41 \%)$ was chosen as the optimum ratio to avoid solvents wasting.

Extraction temperature was set at $30,40,50,60,70,80,90^{\circ} \mathrm{C}$ with particle size of $150-200$ mesh, water to raw material ratio of $60: 1(\mathrm{~mL} / \mathrm{g})$, extraction time of $20 \mathrm{~min}$, ultrasonic amplitude of $30 \%$. As shown in Figure $1 \mathrm{C}$, extraction yield and extraction rate of polysaccharides had no significant increase when extraction temperature was increased from 30 to $50{ }^{\circ} \mathrm{C}(P>0.05)$. When extraction temperature increased from 50 to $70^{\circ} \mathrm{C}$, it had a positive effect on extraction yield and extraction rate $(P<0.05)$. No significant changes were observed on extraction yield and extraction rate slightly decreased with increasing temperature from 70 to $90{ }^{\circ} \mathrm{C}(P<0.05)$. High temperature could increase the dissolution of polysaccharides from the material. Too high temperature may lead to the degradation of polysaccharides [31,32]. Extraction temperature of $70{ }^{\circ} \mathrm{C}$ was selected as the optimum extraction temperature, in which extraction yield and extraction rate were the highest $(22.44 \pm 1.96 \%$ and $17.73 \pm 0.70 \%)$.

Samples with particle size of 150-200 mesh were dissolved at ratio of 60:1 (mL/g) and treated at ultrasonic amplitude of $30 \%$ and extraction temperature of $60^{\circ} \mathrm{C}$ for various times $(5,10,20,30,40,50 \mathrm{~min})$. As shown in Figure 1D, extraction time displayed positive effects on extraction yield and extraction rate when increased from 5 to $40 \mathrm{~min}(P<0.05)$. No significant change was observed in extraction yield $(P>0.05)$ and significant decrease in extraction rate was observed when extraction time was further prolonged to $50 \mathrm{~min}$. Ultrasound treatment could enhance the release and diffusion of polysaccharides easily into the solvents but long-time exposure to ultrasound treatment may induce their breakage and degradation [33-35]. Thus, extraction time of $40 \mathrm{~min}$ was selected as optimum extraction time which had higher extraction yield $(24.29 \pm 2.83 \%)$ and the highest extraction rate $(22.09 \pm 2.58 \%)$.

Ultrasonic amplitude was one of the key factors and it was set at 20,30,40\%. Other extraction conditions were as following: particle size of 150-200 mesh, water to raw material ratio of 60:1 (mL/g), extraction temperature of $60^{\circ} \mathrm{C}$, extraction time of $20 \mathrm{~min}$. As shown in Figure 1E, extraction yield and extraction rate increased significantly $(P<0.05)$ with increasing ultrasonic amplitude. Increase in ultrasonic amplitude could strengthen the effect of cavitations and promote cell wall fragmentation, which increased the diffusion and dissolution of polysaccharides [29]. Ultrasonic amplitude of $40 \%$ was chosen as the optimum level for further study where the highest extraction yield $(27.76 \pm 2.68 \%)$ $(P<0.05)$ and extraction rate $(23.59 \pm 1.03 \%)(P<0.05)$ were observed.

\subsection{Effects of Single-Factor by Hot Water Extraction on Extraction Yield and Extraction Rate of Polysaccharides from Auricularia cornea var. Li.}

Figure 2A-D showed the effects of 4 factors (particle size, water to raw material ratio, extraction temperature, extraction time) by HWE on extraction yield and extraction rate of ACP. Effects of particle size (40-200 mesh) on extraction yield and extraction rate in HWE were shown in Figure 2A. Extraction yield had no significant change $(P>0.05)$ when particle size decreased from 40 to 80 mesh. However, extraction yield increased significantly from $8.15 \pm 0.71 \%$ to $30.24 \pm 1.72 \%$ as particle 
size decreased from 80-100 to 150-200 mesh $(P<0.05)$. Extraction rate of polysaccharides increased significantly from $2.96 \pm 0.14 \%$ to $21.68 \pm 2.83 \%$ as particle size decreased from $40-60$ mesh to 150-200 mesh $(P<0.05)$. Thus, optimum particle size was 150-200 mesh which showed the highest extraction yield $(30.24 \pm 1.72 \%)$ and extraction rate $(21.68 \pm 2.83 \%)(P<0.05)$. As shown in Figure $2 \mathrm{~B}$, extraction yield of polysaccharides had no significant change when water to raw material ratio ranged from 30:1 to 50:1 $(P>0.05)$. There was a slight increase from 50:1 to 60:1. No significant difference was observed between samples with ratio of 60:1 and 70:1 $(P>0.05)$. However, extraction yield decreased rapidly from $30.20 \pm 1.03 \%$ to $23.72 \pm 1.61 \%$ when water to raw material ratio ranged from $70: 1$ to 100:1 $(P<0.05)$ and had no significant change with ratio increasing from 90:1 to 100:1. No significant decrease in extraction rate was observed as ratio increased from 70:1 to 100:1. Thus, water to raw material ratio of $60: 1$ had the highest extraction yield $(30.73 \pm 2.15 \%)$ and extraction rate $(27.60 \pm 1.51 \%)$ and was selected as the optimal ratio. Effects of different extraction temperature $\left(30-90{ }^{\circ} \mathrm{C}\right)$ on extraction yield and extraction rate were shown in Figure 2C. Extraction yield had no significant increase when extraction temperature increased from 30 to $60{ }^{\circ} \mathrm{C}(P>0.05)$. Extraction yield and extraction rate increased rapidly within the increase of extraction temperature from 60 to $90{ }^{\circ} \mathrm{C}$ $(P<0.05)$. Therefore, the optimum extraction temperature in HWE was $90^{\circ} \mathrm{C}$. Effects of extraction time on extraction yield and extraction rate were studied with different extraction time of $0.5,1.0,1.5$, 2.0, 2.5, 3.0, 3.5, $4.0 \mathrm{~h}$ (Figure 2D). Extraction yield increased from $16.33 \pm 0.76 \%$ to $30.86 \pm 1.92 \%$ with the extending of extraction time from 0.5 to $3.0 \mathrm{~h}(P<0.05)$ and had no significant increase $(P>0.05)$ when extraction time exceeded from 3.0 to $4.0 \mathrm{~h}$. Extraction rate increased significantly with extraction time increasing from 2.5 to $3.0 \mathrm{~h}(P<0.05)$. Higher extraction yield $(30.86 \pm 1.92 \%)$ and the highest extraction rate $(26.43 \pm 1.45 \%)$ were obtained when extraction time increased to $3.0 \mathrm{~h}$. Thus, optimum extraction time in HWE was $3.0 \mathrm{~h}$.
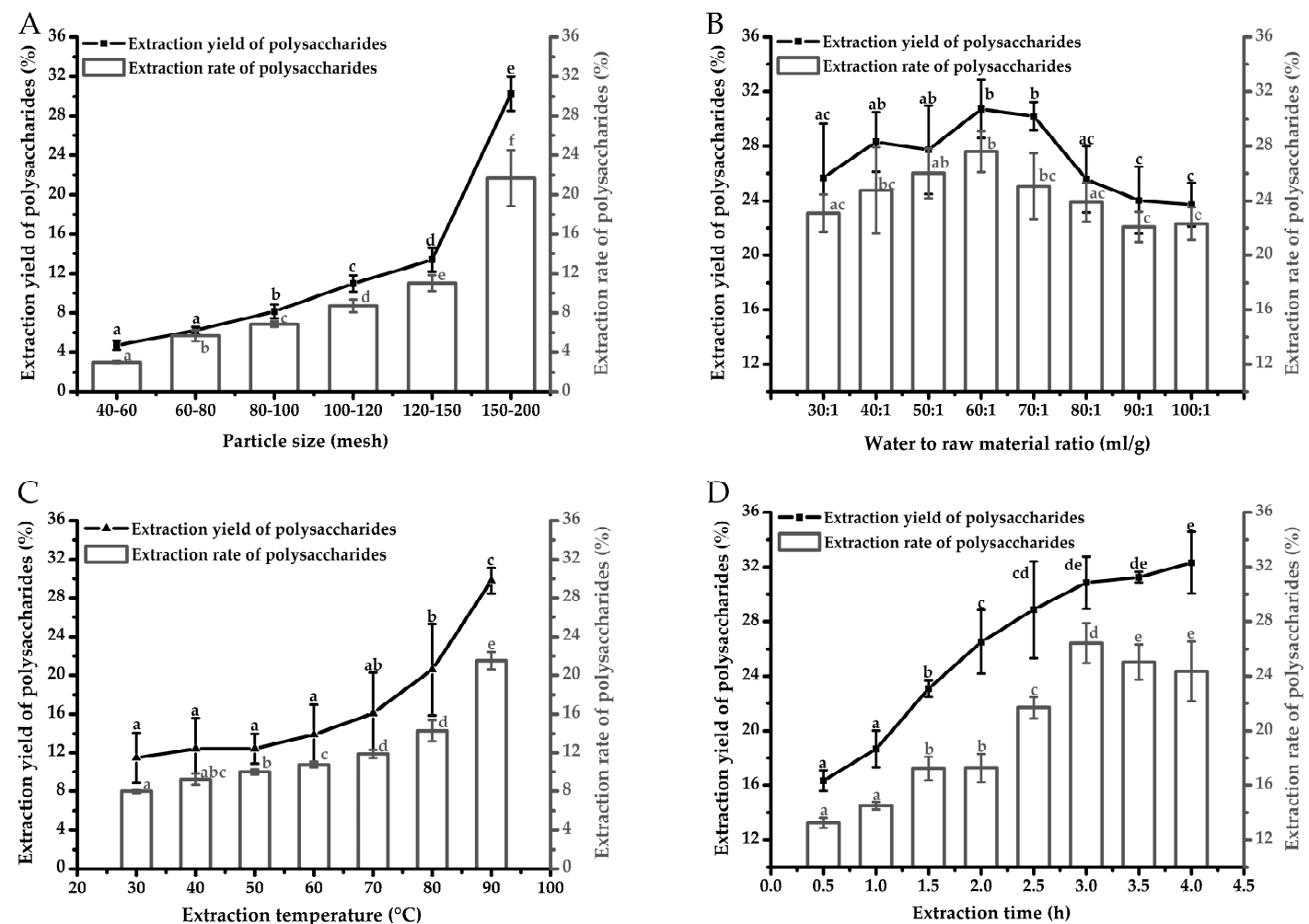

Figure 2. Effects of single-factor (A) particle size, (B) water to raw material ratio, (C) extraction temperature, (D) extraction time by hot water extraction on extraction yield and extraction rate of polysaccharides from Auricularia cornea var. Li. Values with different letters are significantly different $(P<0.05)$ for extraction yield and extraction rate of polysaccharides. 
2.3. Extraction Yield, Extraction Rate, Purity of Polysaccharides by Ultrasound-assisted Extraction and Hot Water extraction

Optimized extraction conditions of UAE and HWE were summarized in Table 1. The optimum conditions of UAE were shown as follows: particle size of 150-200 mesh, water to raw material ratio of 70:1 (mL/g), extraction temperature at $70{ }^{\circ} \mathrm{C}$ for $40 \mathrm{~min}$, ultrasonic amplitude of $40 \%$. The optimum conditions of HWE were shown as follows: particle size of 150-200 mesh, water to raw material ratio of $60: 1$ (mL/g), extraction temperature at $90{ }^{\circ} \mathrm{C}$ for $3.0 \mathrm{~h}$. As shown in Table 1, extraction yield of polysaccharides by UAE $(30.99 \pm 1.93 \%)$ with shorter extraction time had no significant difference with that of $\operatorname{HWE}(30.35 \pm 1.67 \%)(P>0.05)$. Extraction rate $(29.29 \pm 1.41 \%)$ and purity $(88.62 \pm 2.80 \%)$ of polysaccharides by UAE were all higher than those (extraction rate of $24.95 \pm 2.78 \%$ and purity of $75.33 \pm 6.15 \%)$ by $\operatorname{HWE}(P<0.05)$.

Table 1. Comparison of extraction yield, extraction rate, purity of polysaccharides from Auricularia cornea var. Li. (ACP) extracted by hot water extraction (HWE) or ultrasound assisted extraction (UAE).

\begin{tabular}{ccc}
\hline Methods & HWE & UAE \\
\hline Particle size (mesh) & $150-200$ & $150-200$ \\
Extraction time & $60: 1$ & $70: 1$ \\
Water to raw material ratio $(\mathrm{mL} / \mathrm{g})$ & $3.0 \mathrm{~h}$ & $40 \mathrm{~min}$ \\
Extraction temperature $\left({ }^{\circ} \mathrm{C}\right)$ & 90 & 70 \\
Ultrasonic amplitude $(\%)$ & $30.35 \pm 1.67^{\mathrm{a}}$ & $30.99 \pm 1.93^{\mathrm{a}}$ \\
Extraction yield of polysaccharides $(\%)$ & $24.95 \pm 2.78^{\mathrm{a}}$ & $29.29 \pm 1.41^{\mathrm{b}}$ \\
Extraction rate of polysaccharides $(\%)$ & $75.33 \pm 6.15^{\mathrm{a}}$ & $88.62 \pm 2.80^{\mathrm{b}}$ \\
\hline Purity of polysaccharides $(\%)$ &
\end{tabular}

Note: Different letters in row indicate significant differences at $P<0.05$.

\subsection{Microstructure}

Microstructure of Auricularia cornea var. Li. and residues treated by UAE and HWE were observed and the images were shown in Figure 3A-C. Ultrasound-assisted extraction and hot water extraction methods resulted in different physical changes of residues. Compared with untreated material, microstructure of residues treated by HWE had no significant difference, while residues treated by UAE showed significant change. Heated solvent in HWE diffused slowly through the cell walls, dissolved and carried away polysaccharides slowly, which had weak effect on cell tissues of material [16]. By contrast, ultrasound treatment could produce acoustic cavitation in liquids which could induce physical changes [36] and the cell tissues of residues treated by UAE (Figure 3C) were explosively disrupted which was benefit for the diffusion of polysaccharides [7]. Scanning Electron Microscopy (SEM) images of residues extracted after ultrasound treatment showed that more broken cells with rod-like shape may be responsible for the high extraction rate of polysaccharides.

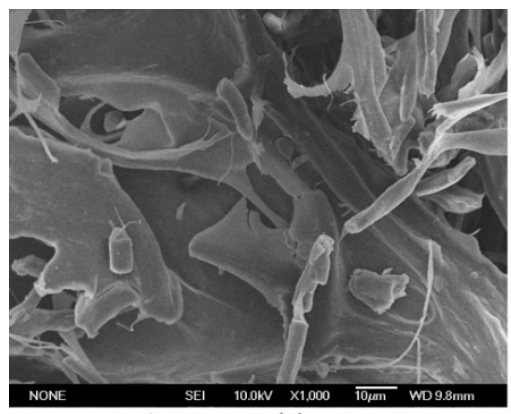

A raw material

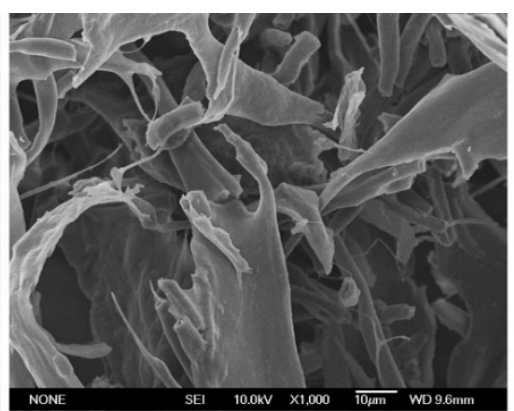

$B$ residues treated by HWE

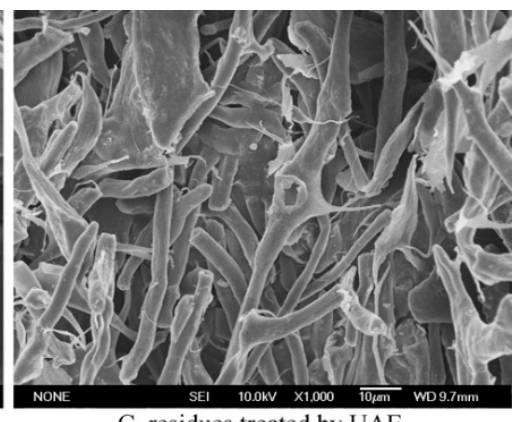

$\mathrm{C}$ residues treated by $\mathrm{UAE}$

Figure 3. Scanning Electron Microscopy (SEM) images of Auricularia cornea var. Li. (A) raw material, (B) residues treated by HWE, (C) residues treated by UAE. 


\subsection{Fourier Transform Infrared Spectra}

Figure 4 showed the Fourier Transform Infrared (FTIR) spectra of dialyzed ACP (DACP)-HWE and DACP-UAE, which had virtually identical characteristic absorption peaks. Two characteristic absorptions of polysaccharides, the strong and broad peaks at around $3390.9 \mathrm{~cm}^{-1}$ (DACP-HWE) and $3367.7 \mathrm{~cm}^{-1}$ (DACP-UAE) for $\mathrm{O}-\mathrm{H}$ stretching vibrations and the weak peaks at around $2926.0 \mathrm{~cm}^{-1}$ (DACP-HWE) and $2931.8 \mathrm{~cm}^{-1}$ (DACP-UAE) for C-H stretching vibrations were observed, respectively [37,38]. The bands at approximately $1730.1 \mathrm{~cm}^{-1}$ (DACP-HWE), $1732.1 \mathrm{~cm}^{-1}$ (DACP-UAE), $1637.6 \mathrm{~cm}^{-1}$ (DACP-HWE), $1641.4 \mathrm{~cm}^{-1}$ (DACP-UAE) were attributed to stretching vibration of $\mathrm{C}=\mathrm{O}[28,39]$. The weak peaks observed at $1421.5 \mathrm{~cm}^{-1}$ (DACP-HWE), $1423.5 \mathrm{~cm}^{-1}$ (DACP-UAE) and $1375.2 \mathrm{~cm}^{-1}$ indicated the stretching vibration of $\mathrm{C}-\mathrm{H}$ [40]. Peaks observed at $1247.9 \mathrm{~cm}^{-1}, 1076.3 \mathrm{~cm}^{-1}$ and $1041.6 \mathrm{~cm}^{-1}$ may be assigned to the contribution of $\mathrm{C}-\mathrm{O}-\mathrm{C}$ symmetric stretching vibration $[13,41,42]$. Absorption peaks at $895.0 \mathrm{~cm}^{-1}$ suggested the presence of $\beta$-configurations in the molecular structure of DACP-HWE and DACP-UAE $[42,43]$. The FTIR spectra showed all typical absorption peaks associated with polysaccharides which confirmed the identity of DACP-HWE and DACP-UAE as polysaccharides.

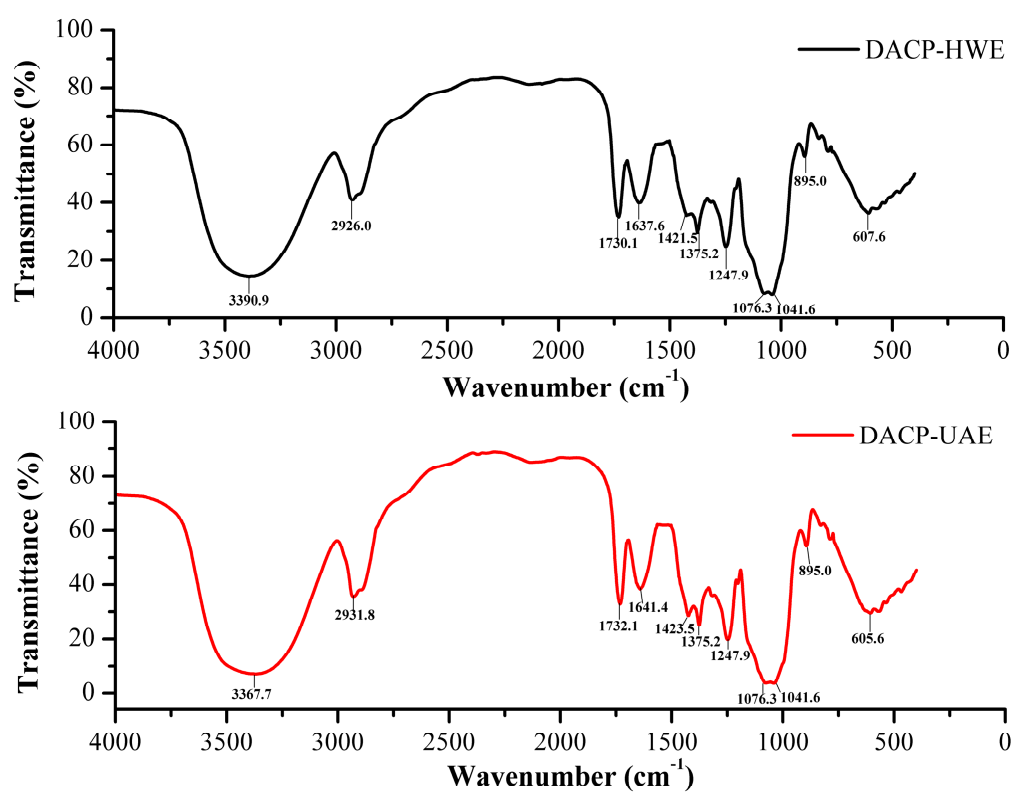

Figure 4. Fourier Transform Infrared (FTIR) spectra of dialyzed ACP (DACP)-HWE and DACP-UAE.

\subsection{Rheological Properties}

\subsubsection{Steady-Shear Flow Property}

The flow properties of DACP-HWE and DACP-UAE solutions with different concentrations $(5,10,20 \mathrm{mg} / \mathrm{mL})$ were investigated using steady shear flow sweeps in the shear rate range of 0.01-1000 s $\mathrm{s}^{-1}$ (Figure 5). The apparent viscosity of DACP-HWE and DACP-UAE solutions with different concentrations decreased with increased shear rate and all showed typical shear-thinning behaviors. Similar results were observed for polysaccharides of Auricularia auricular-judae and other polysaccharides $[19,21,44]$. The flow curves of DACP-UAE were similar with those of DACP-HWE that apparent viscosity increased significantly with increase of the concentrations in the shear rate range of 0.01-1000 s $\mathrm{s}^{-1}$. As shown in Figure 5, when concentration of DACP-HWE and DACP-UAE solutions were increased from 5 to $20 \mathrm{mg} / \mathrm{mL}$, apparent viscosity at shear rate of $0.1 \mathrm{~s}^{-1}$ were increased from 4.92 to 74.76 Pa.s and from 0.09 to 2.14 Pa.s, respectively. Increased entanglement and aggregation of molecule chains at higher concentrations may be responsible for higher viscosity [45]. However, apparent viscosity of DACP-UAE was significantly lower than that of DACP-HWE with 
same concentration at the same shear rate. Similar results were observed for schizophyllan [20]. Decrease in apparent viscosity of DACP after ultrasound treatment could be attributed to the reduction in molecular weight [21,46-48].

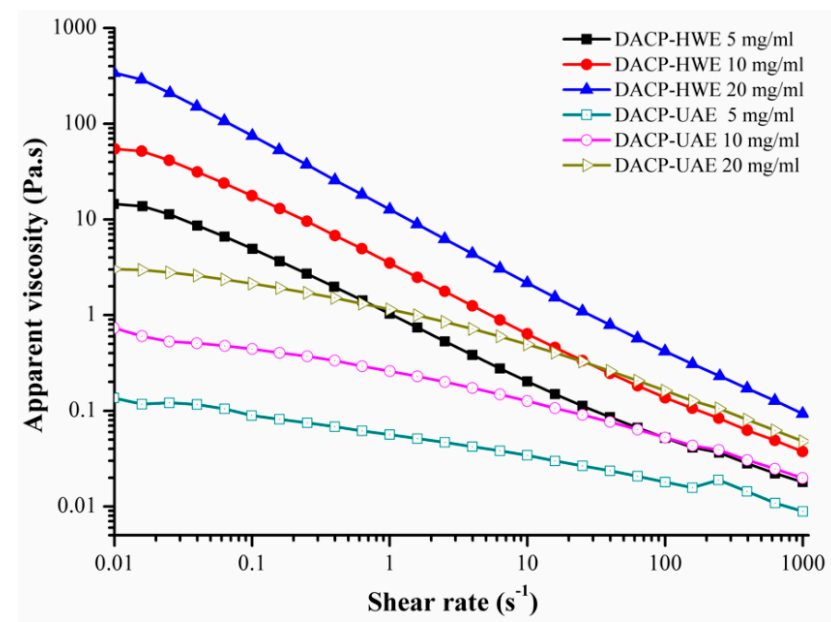

Figure 5. Steady shear flow curves of DACP-HWE and DACP-UAE solutions with different concentrations $(5,10,20 \mathrm{mg} / \mathrm{mL})$ as a function of shear rate.

All samples were determined for apparent viscosity by flow temperature ramp at shear rate of $10 \mathrm{~s}^{-1}$ (Figure 6). The results were consistent with the steady flow curves and apparent viscosity increased with increase of concentration. Apparent viscosity of DACP-HWE solutions was higher than that of DACP-UAE at same concentration. Both DACP-HWE and DACP-UAE solutions showed temperature-independent behaviors, indicating the non-sensitivity of temperature at 25 to $90{ }^{\circ} \mathrm{C}$. Similar results were reported for polysaccharides of Auricularia auricular-judae [19].

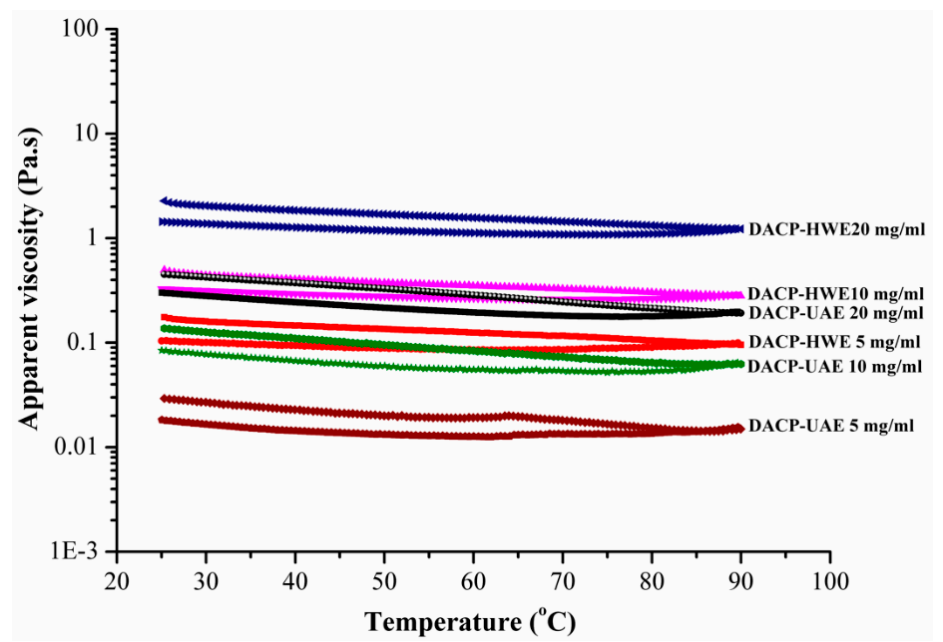

Figure 6. Steady shear flow curves of DACP-HWE and DACP-UAE solutions with different concentrations $(5,10,20 \mathrm{mg} / \mathrm{mL})$ as a function of temperature $\left(25-90^{\circ} \mathrm{C}\right)$.

\subsubsection{Dynamic Viscoelastic Property}

Frequency-dependent behaviors of DACP-HWE and DACP-UAE solutions with different concentrations were examined within the linear viscoelastic range (LVR) at frequency range of 0.1-100 rad/s (Figure 7A,B). Storage modulus $\left(\mathrm{G}^{\prime}\right)$ and loss modulus (G') of DACP-HWE and DACP-UAE solutions were observed as a function of frequency $(\omega)$ and all increased with increasing frequency. For DACP-HWE solutions at the concentrations of 10 and $20 \mathrm{mg} / \mathrm{mL}, \mathrm{G}^{\prime}$ were higher than $G^{\prime \prime}$ within the frequency range (0.1-100 rad/s) and both had a tendency to approach each other 
at a high frequency (no crossover point occurred), which exhibited the typical gel-like behaviors. Similar results have been reported in previous studies $[19,20]$. The DACP-HWE solution at $5 \mathrm{mg} / \mathrm{mL}$ exhibited a transition from a gel-like to a fluid-like structure in which $G^{\prime}$ was higher than $G^{\prime \prime}$ in low frequency range followed by the domination of $G^{\prime \prime}$ with a crossover point at a high frequency. The crossover point occurred at $\omega=77.61 \mathrm{rad} / \mathrm{s}$ and $\mathrm{G}^{\prime}=\mathrm{G}^{\prime \prime}=3.40 \mathrm{~Pa}$. For DACP-UAE solutions of $5 \mathrm{mg} / \mathrm{mL}$ and $10 \mathrm{mg} / \mathrm{mL}, \mathrm{G}^{\prime \prime}$ were higher than $\mathrm{G}^{\prime}$ in the frequency range $(0.1-100 \mathrm{rad} / \mathrm{s})$ and both had a tendency to approach each other at a high frequency which exhibited the typical fluid-like behaviors [49]. As the increase of concentration, DACP-UAE solution at $20 \mathrm{mg} / \mathrm{mL}$ exhibited the transition from a fluid-like to a gel-like structure in which $G^{\prime \prime}$ was higher than $G^{\prime}$ in low frequency range followed by the domination of $G^{\prime}$ with a crossover point at a high frequency. The crossover point occurred at $\omega=86.89 \mathrm{rad} / \mathrm{s}$ and $\mathrm{G}^{\prime}=\mathrm{G}^{\prime \prime}=11.01 \mathrm{~Pa}$. Ultrasound treatment decreased the elastic behavior and increased the viscous system of ACP [20].
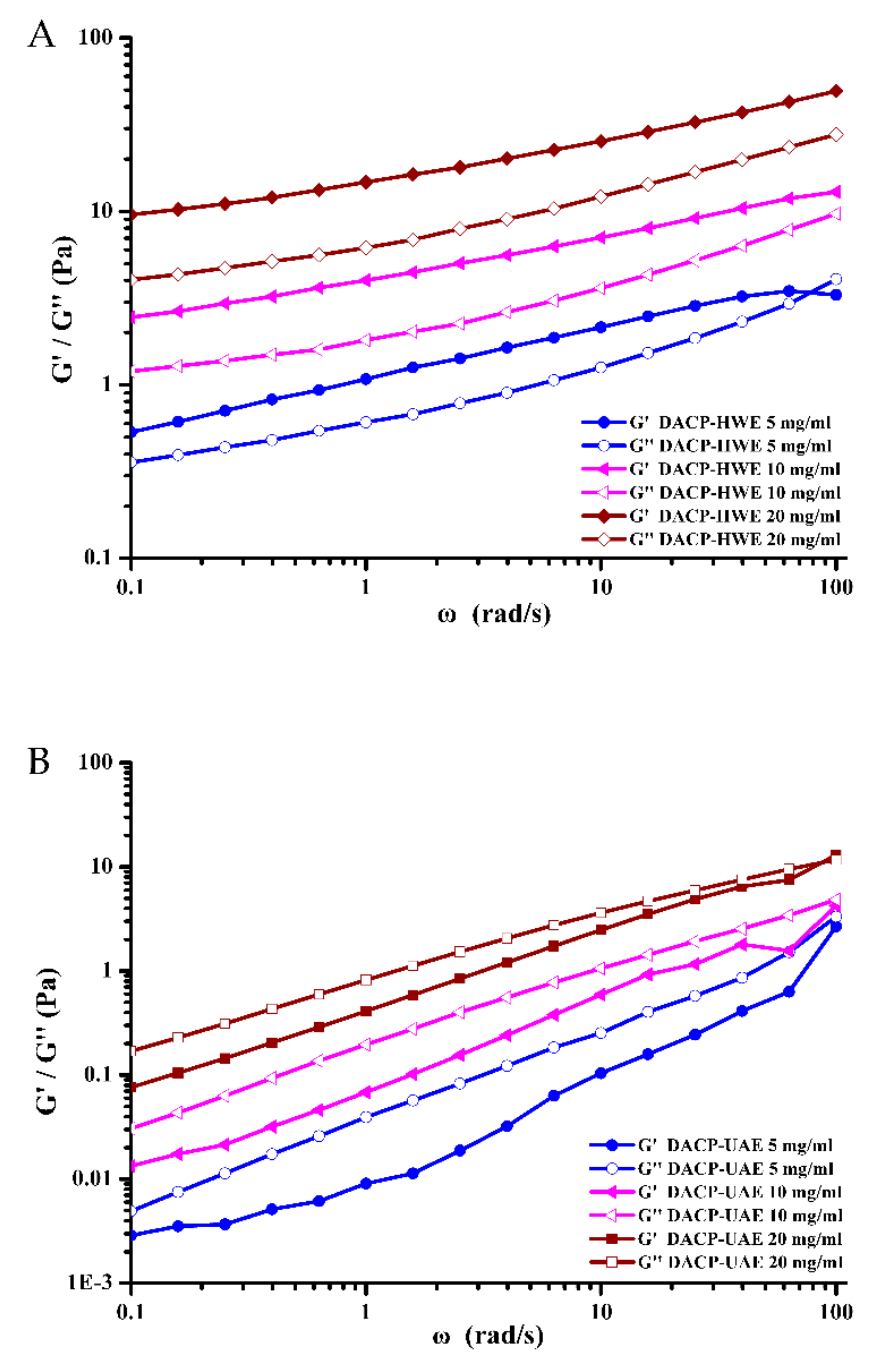

Figure 7. Dynamic storage modulus $\left(\mathrm{G}^{\prime}\right)$ and loss modulus $\left(\mathrm{G}^{\prime \prime}\right)$ with oscillatory frequency sweeps of (A) DACP-HWE solutions with different concentrations $(5,10,20 \mathrm{mg} / \mathrm{mL})$ and (B) DACP-UAE solutions with different concentrations $(5,10,20 \mathrm{mg} / \mathrm{mL})$.

\section{Materials and Methods}

\subsection{Materials}

Auricularia cornea var. Li. ("Yu Mu Er") was purchased from Jilin Agricultural University, China. The standard monosaccharide (D-glucose) was purchased from Sigma (St. Louis, MO, USA). 
Dialysis membranes (molecular weight cut off, $8 \mathrm{kDa}$ ) were purchased from Solarbio (Beijing, China). All other chemicals were of reagent grade and purchased from Beijing Chemical Works (Beijing, China). Deionized water used in this study was made by Millipore Milli- $\mathrm{Q}^{\mathrm{TM}}$ water purification system (Millipore Corp., Bedford, MA, USA).

\subsection{Extraction of Polysaccharides from Auricularia cornea var. Li.}

Auricularia cornea var. Li. was dried in an oven at $45^{\circ} \mathrm{C}$ until its moisture content was less than 3\%. Then the dried sample was ground using a high speed mill (FW100, Tianjin, China) and sieved into powders with a series of standard sieves (Shaoxing, Zhejiang, China) with various particle sizes $(40,60,80,100,120,150,200$ mesh size screen). The sieves were consistent with National Standard (GB/T 6003.1-2012). Crude polysaccharides from Auricularia cornea var. Li. (ACP) were extracted using UAE and HWE and the detailed extraction process was shown in Figure 8.

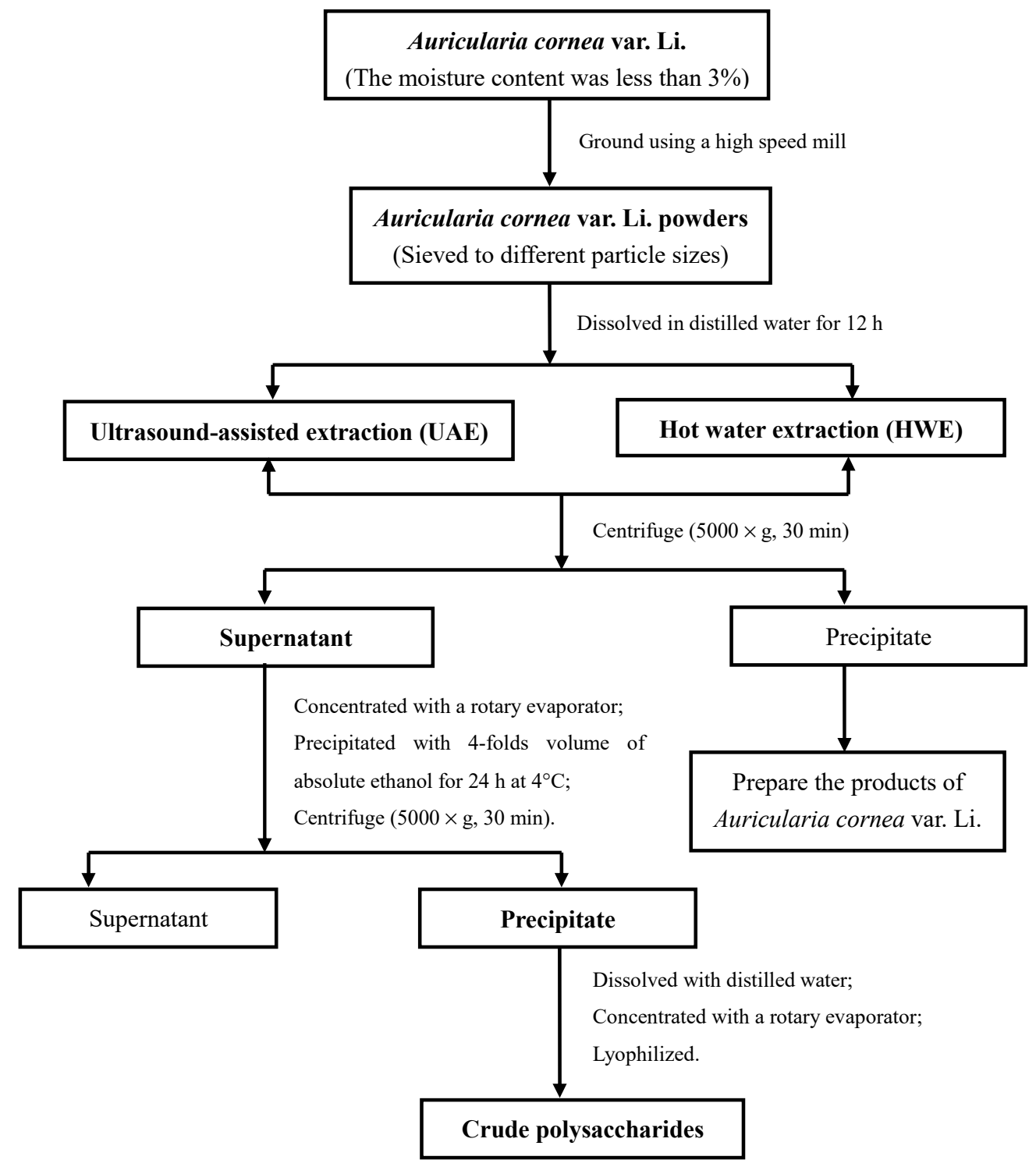

Figure 8. Flow chart and experimental design for the extraction process of polysaccharides from Auricularia cornea var. Li. 
3.2.1. Ultrasound-assisted Extraction of Polysaccharides from Auricularia cornea var. Li.

Ultrasound-assisted Extraction (UAE) was performed in a $800 \mathrm{~W}, 20 \mathrm{kHz}$ ultrasonic processor (VCX800, vibra cell, Sonics, Newtown, CT, USA) with a $13 \mathrm{~mm}$ high grade titanium alloy probe (amplitude, $114 \mu \mathrm{m}$ ) threaded to a $3 \mathrm{~mm}$ tapered microtip to sonicate the Auricularia cornea var. Li. powder dispersions in a 200-ml jacketed glass beaker [50]. Auricularia cornea var. Li. powder (2.0 g) under designated size was mixed with distilled water (water to raw material ratio of 30:1-100:1, $\mathrm{mL} / \mathrm{g}$ ) in conical flasks and stirred using magnetic stirrers (IKA Ared, Pedrollo, Italy) for sufficient dissolution and then treated with ultrasonic probe $(20 \mathrm{kHz})$ at certain extraction temperature and ultrasonic amplitude for required time. The extraction temperature was preset with thermostatic temperature control and the pulse duration was on-time $10 \mathrm{~s}$ and off-time $5 \mathrm{~s}$. Effects of particle size (40-200 mesh), water to raw material ratio (30:1-100:1, $\mathrm{mL} / \mathrm{g})$, extraction temperature $\left(30-90{ }^{\circ} \mathrm{C}\right)$, extraction time (5-50 $\mathrm{min}$ ) and ultrasonic amplitude (20-40\%) were studied by a single-factor experiment. After extraction, the extract was centrifuged at $5000 \times g$ for $30 \mathrm{~min}$ using a centrifuge (Avanti ${ }^{\circledR}$ J-E, Beckman Coulter, Calif., USA). The supernatant was concentrated with a rotary evaporator (N-1100, EYELA, Tokyo, Japan) and precipitated with 4-folds volume of absolute ethanol for $24 \mathrm{~h}$ at $4{ }^{\circ} \mathrm{C}$. The polysaccharides precipitate was obtained by centrifugation at $5000 \times g$ for $30 \mathrm{~min}$ and then dissolved in distilled water. Polysaccharides solutions were removed for residual ethanol and concentrated with the rotary evaporator (N-1100, EYELA, Tokyo, Japan); and lyophilized (Alpha 1-2 LDplus, CHRIST, Osterode am Harz, Germany) to obtain crude polysaccharides.

\subsubsection{Hot Water Extraction of Polysaccharides from Auricularia cornea var. Li.}

Auricularia cornea var. Li. powder $(2.0 \mathrm{~g})$ was mixed with distilled water (water to raw material ratio of 30:1-100:1, $\mathrm{mL} / \mathrm{g}$ ) in conical flasks and stirred using magnetic stirrers for sufficient dissolution and then extracted under water bath condition with designated particle size (40-200 mesh), extraction temperature $\left(30-90^{\circ} \mathrm{C}\right)$ and extraction time $(0.5-4 \mathrm{~h})$. The following processes for obtaining the crude polysaccharides were similar to UAE.

\subsubsection{Calculation of Extraction Yield, Extraction Rate, Purity}

Polysaccharides content was determined by phenol-sulfuric acid method using D-glucose as standard reference [51]. Extraction yield (\%), extraction rate (\%) and purity (\%) were calculated using following equations according to previous studies $[7,26,40]$ :

$$
\begin{gathered}
\text { Extraction yield }(\%)=W_{1} / W_{0} \times 100 \\
\text { Extraction rate }(\%)=W_{2} / W_{0} \times 100 \\
\text { Purity }(\%)=W_{2} / W_{1} \times 100
\end{gathered}
$$

where $W_{0}$ is the weight of dried Auricularia cornea var. Li. powder (g), $W_{1}$ is the weight of dried crude polysaccharides $(\mathrm{g}), W_{2}$ is the content of polysaccharides $(\mathrm{g})$.

\subsection{Scanning Electron Microscopy Analysis}

To investigate the effect of HWE and UAE on the microstructure of materials, Scanning Electron Microscopy (SEM) was used to reveal the shape and surface characteristics of samples after extraction [16]. Dried samples (raw material, residues treated by UAE and HWE) of Auricularia cornea var. Li. were fixed on a specimen holder with the help of doubled-sided adhesive tapes and then sputtered with gold powder. Microstructure was obtained using a Scanning Electron Microscope (JMS-6700F, JEOL Co., Tokyo, Japan) at a $10 \mathrm{kV}$ acceleration voltage. 


\subsection{Fourier Transform Infrared Spectroscopy Analysis}

Under the optimum conditions, crude polysaccharides from Auricularia cornea var. Li. (ACP) extracted by HWE and UAE were dialyzed using dialysis membranes (molecular weight cut off, $8 \mathrm{kDa}$ ) against distilled water for $24 \mathrm{~h}$ with the stirring of magnetic stirrer, then lyophilized. The dialyzed ACP extracted by HWE and UAE was abbreviated as DACP-HWE and DACP-UAE.

Fourier Transform Infrared (FTIR) spectra of DACP-HWE and DACP-UAE were analyzed using an IR Prestige-21 Spectrometer (Shimadzu Co, Ltd, Kyoto, Japan) in the range of $400-4000 \mathrm{~cm}^{-1}$. Approximately $2 \mathrm{mg}$ samples (DACP-HWE and DACP-UAE) were mixed with $200 \mathrm{mg}$ dried $\mathrm{KBr}$ and then pressed into pellets for FTIR measurement [52].

\subsection{Rheological Property Measurements}

\subsubsection{Sample Preparation}

The dialyzed samples (DACP-HWE and DACP-UAE) were dispersed in deionized water at different concentrations $(5,10,20 \mathrm{mg} / \mathrm{mL})$ and stirred for sufficient dissolution at room temperature. Dispersions were kept at $4{ }^{\circ} \mathrm{C}$ overnight to enable biopolymer hydration and release of bubbles [53].

\subsubsection{Steady-Shear Flow Property}

Rheological measurements of DACP-HWE and DACP-UAE solutions were carried out using a rheometer (DHR-1, TA Instrument, New Castle, DE, USA) with a aluminum parallel plate geometry (diameter $=60 \mathrm{~mm}$, plate spacing $=1 \mathrm{~mm}$ ) [54]. Samples were placed on the plate of rheometer and excessive samples were wiped off with a clean paper towel.

Flow sweep analysis was conducted on DACP-HWE and DACP-UAE solutions with different concentrations at shear rate ranging from 0.01 to $1000 \mathrm{~s}^{-1}$ at $25^{\circ} \mathrm{C}$. Apparent viscosity was recorded as a function of shear rate.

Flow temperature sweep analysis at the shear rate of $10 \mathrm{~s}^{-1}$ was performed on DACP-HWE and DACP-UAE solutions with different concentrations from initial temperature of $25^{\circ} \mathrm{C}$ to $90{ }^{\circ} \mathrm{C}$ with a rising rate of $3{ }^{\circ} \mathrm{C} / \mathrm{min}$ and then cooled to $25^{\circ} \mathrm{C}$ at the same rate.

\subsubsection{Dynamic Viscoelastic Property}

For the dynamic oscillatory frequency sweep analysis, variations in storage modulus $\left(G^{\prime}\right)$ and loss modulus $\left(G^{\prime \prime}\right)$ of DACP-HWE and DACP-UAE solutions as a function of frequency $(\omega)(0.1-100 \mathrm{rad} / \mathrm{s})$ were tested at $25^{\circ} \mathrm{C}$. Before tests, the linear viscoelastic range (LVR) of DACP-HWE and DACP-UAE solutions with different concentrations were established using strain sweeps at a constant frequency of $1 \mathrm{~Hz}$ (Figure S1). Frequency sweeps were performed with a strain of $5 \%$ which was within the linear viscoelastic range for all samples.

\subsection{Statistical Analysis}

All experiments were performed in triplicate. Statistical analyses were carried out using statistical program IBM SPSS Statistics Version 21.0. (SPSS Inc. Chicago, IL, USA). Comparisons among data of different groups were performed with One-way ANOVA, where LSD method and Dunnet'T3 were used on the basis of the homogeneity test. Results were presented as mean \pm standard deviation (SD) and considered significantly different when $P<0.05$ at $95 \%$ level of confidence. Figures were drawn using Origin 8.0 (Origin lab Corp., Northampton, MA, USA).

\section{Conclusions}

Ultrasound-assisted extraction was an effective method for extracting polysaccharides from Auricularia cornea via. Li. It showed high extraction rate and the extracted polysaccharides have 
high purity, relatively low apparent viscosity and liquid-like behavior. The preliminary structure of polysaccharides was not changed by UAE compared with conventional hot water extraction method.

Supplementary Materials: The following are available online, Figure S1: The Linear Viscoelastic Range (LVR) of DACP-HWE and DACP-UAE solutions with different concentrations $(5,10,20 \mathrm{mg} / \mathrm{mL})$

Author Contributions: Y.W. performed the experiments. Y.W. and C.W. analyzed the data. Y.W. wrote the manuscript. C.W. and M.G. revised the manuscript. M.G. supervised the research.

Funding: This research was funded by the Matching Funds Project of Northeast Agricultural University.

Conflicts of Interest: The authors declare no conflict of interest.

\section{References}

1. Xue, Z.; Hao, J.; Yu, W.; Kou, X. Effects of Processing and Storage Preservation Technologies on Nutritional Quality and Biological Activities of Edible Fungi: A Review. J. Food Process. Eng. 2017, 40, e12437. [CrossRef]

2. Zeng, W.C.; Zhang, Z.; Gao, H.; Jia, L.R.; Chen, W.Y. Characterization of antioxidant polysaccharides from Auricularia auricular using microwave-assisted extraction. Carbohydr. Polym. 2012, 89, 694-700. [CrossRef] [PubMed]

3. Jeff, I.B.; Li, S.; Peng, X.; Kassim, R.M.; Liu, B.; Zhou, Y. Purification, structural elucidation and antitumor activity of a novel mannogalactoglucan from the fruiting bodies of Lentinus edodes. Fitoterapia 2013, 84, 338-346. [CrossRef] [PubMed]

4. Ma, G.; Yang, W.; Mariga, A.M.; Fang, Y.; Ma, N.; Pei, F.; Hu, Q. Purification, characterization and antitumor activity of polysaccharides from Pleurotus eryngii residue. Carbohydr. Polym. 2014, 114, 297-305. [CrossRef] [PubMed]

5. Yang, W.; Pei, F.; Shi, Y.; Zhao, L.; Fang, Y.; Hu, Q. Purification, characterization and anti-proliferation activity of polysaccharides from Flammulina velutipes. Carbohydr. Polym. 2012, 88, 474-480. [CrossRef]

6. Ye, M.; Qiu, T.; Peng, W.; Chen, W.-X.; Ye, Y.-W.; Lin, Y.-R. Purification, characterization and hypoglycemic activity of extracellular polysaccharides from Lachnum calyculiforme. Carbohydr. Polym. 2011, 86, 285-290. [CrossRef]

7. Zhu, Y.; Li, Q.; Mao, G.; Zou, Y.; Feng, W.; Zheng, D.; Wang, W.; Zhou, L.; Zhang, T.; Yang, J.; et al. Optimization of enzyme-assisted extraction and characterization of polysaccharides from Hericium erinaceus. Carbohydr. Polym. 2014, 101, 606-613. [CrossRef] [PubMed]

8. Wang, J.; Zhang, J.; Zhao, B.; Wang, X.; Wu, Y.; Yao, J. A comparison study on microwave-assisted extraction of Potentilla anserina L. polysaccharides with conventional method: Molecule weight and antioxidant activities evaluation. Carbohydr. Polym. 2010, 80, 84-93. [CrossRef]

9. Cheong, K.L.; Wang, L.Y.; Wu, D.T.; Hu, D.J.; Zhao, J.; Li, S.P. Microwave-Assisted Extraction, Chemical Structures, and Chain Conformation of Polysaccharides from a Novel Cordyceps Sinensis Fungus UM01. J. Food Sci. 2016, 81, C2167-C2174. [CrossRef] [PubMed]

10. Tian, Y.; Zeng, H.; Xu, Z.; Zheng, B.; Lin, Y.; Gan, C.; Lo, Y.M. Ultrasonic-assisted extraction and antioxidant activity of polysaccharides recovered from white button mushroom (Agaricus bisporus). Carbohydr. Polym. 2012, 88, 522-529. [CrossRef]

11. Chiang, C.F.; Lai, L.S. Effect of enzyme-assisted extraction on the physicochemical properties of mucilage from the fronds of Asplenium australasicum (J. Sm.) Hook. Int. J. Biol. Macromol. 2019, 124, 346-353. [CrossRef] [PubMed]

12. Chen, Y.; Yao, F.; Ming, K.; Wang, D.; Hu, Y.; Liu, J. Polysaccharides from Traditional Chinese Medicines: Extraction, Purification, Modification, and Biological Activity. Molecules 2016, 21, 1705. [CrossRef] [PubMed]

13. You, Q.; Yin, X.; Zhang, S.; Jiang, Z. Extraction, purification, and antioxidant activities of polysaccharides from Tricholoma mongolicum Imai. Carbohydr. Polym. 2014, 99, 1-10. [CrossRef] [PubMed]

14. Youssouf, L.; Lallemand, L.; Giraud, P.; Soule, F.; Bhaw-Luximon, A.; Meilhac, O.; D'Hellencourt, C.L.; Jhurry, D.; Couprie, J. Ultrasound-assisted extraction and structural characterization by NMR of alginates and carrageenans from seaweeds. Carbohydr. Polym. 2017, 166, 55-63. [CrossRef] [PubMed]

15. Poommarinvarakul, S.; Tattiyakul, J.; Muangnapoh, C. Isolation and rheological properties of tamarind seed polysaccharide from tamarind kernel powder using protease enzyme and high-intensity ultrasound. J. Food Sci. 2010, 75, E253-E260. [CrossRef] [PubMed] 
16. Ying, Z.; Han, X.; Li, J. Ultrasound-assisted extraction of polysaccharides from mulberry leaves. Food Chem. 2011, 127, 1273-1279. [CrossRef] [PubMed]

17. Ma, F.; Zhang, Y.; Liu, N.; Zhang, J.; Tan, G.; Kannan, B.; Liu, X.; Bell, A.E. Rheological properties of polysaccharides from Dioscorea opposita Thunb. Food Chem. 2017, 227, 64-72. [CrossRef] [PubMed]

18. Wang, W.; Li, C.; Du, G.; Zhang, X.; Zhang, H. Characteristics and Rheological Properties of Polysaccharide Nanoparticles from Edible Mushrooms (Flammulina velutipes). J. Food Sci. 2017, 82, 687-693. [CrossRef] [PubMed]

19. Bao, H.; You, S.; Cao, L.; Zhou, R.; Wang, Q.; Cui, S.W. Chemical and rheological properties of polysaccharides from fruit body of Auricularia auricular-judae. Food Hydrocoll. 2016, 57, 30-37. [CrossRef]

20. Zhong, K.; Zhang, Q.; Tong, L.; Liu, L.; Zhou, X.; Zhou, S. Molecular weight degradation and rheological properties of schizophyllan under ultrasonic treatment. Ultrason. Sonochem. 2015, 23, 75-80. [CrossRef] [PubMed]

21. Li, J.; Li, B.; Geng, P.; Song, A.-X.; Wu, J.-Y. Ultrasonic degradation kinetics and rheological profiles of a food polysaccharide (konjac glucomannan) in water. Food Hydrocoll. 2017, 70, 14-19. [CrossRef]

22. Seshadri, R.; Weiss, J.; Hulbert, G.J.; Mount, J.J.F.H. Ultrasonic processing influences rheological and optical properties of high-methoxyl pectin dispersions. Food Hydrocoll. 2003, 17, 191-197. [CrossRef]

23. Zhao, C.; Liao, Z.; Wu, X.; Liu, Y.; Liu, X.; Lin, Z.; Huang, Y.; Liu, B. Isolation, purification, and structural features of a polysaccharide from Phellinus linteus and its hypoglycemic effect in alloxan-induced diabetic mice. J. Food Sci. 2014, 79, H1002-H1010. [CrossRef] [PubMed]

24. Xiao, L.; Kuotan, Z. A review of the advances of the research on a white variant strain in Genus Auricularia. Edible Med. Mushrooms 2016, 24, 230-233. (In Chinese)

25. Yuchun, C.; Haiying, B.; Xiao, L.; Tolgor, B.; Yu, L. Anti-tumor activities of Auricularia cornea fruiting body extract in $\mathrm{H} 22$ bearing mice. Mycosystema 2017, 26, 1289-1298. (In Chinese) [CrossRef]

26. Miao, Y.-Z.; Lin, Q.; Cao, Y.; He, G.-H.; Qiao, D.-R.; Cao, Y. Extraction of water-soluble polysaccharides (WSPS) from Chinese truffle and its application in frozen yogurt. Carbohydr. Polym. 2011, 86, 566-573. [CrossRef]

27. XuJie, H.; Wei, C. Optimization of extraction process of crude polysaccharides from wild edible BaChu mushroom by response surface methodology. Carbohydr. Polym. 2008, 72, 67-74. [CrossRef]

28. Ponmurugan, K.; Al-Dhabi, N.A.; Maran, J.P.; Karthikeyan, K.; Moothy, I.G.; Sivarajasekar, N.; Manoj, J.J.B. Ultrasound assisted pectic polysaccharide extraction and its characterization from waste heads of Helianthus annus. Carbohydr. Polym. 2017, 173, 707-713. [CrossRef] [PubMed]

29. Hu, H.; Zhao, Q.; Pang, Z.; Xie, J.; Lin, L.; Yao, Q. Optimization extraction, characterization and anticancer activities of polysaccharides from mango pomace. Int. J. Biol. Macromol. 2018, 117, 1314-1325. [CrossRef] [PubMed]

30. Zhao, Z.; Xu, X.; Ye, Q.; Dong, L. Ultrasound extraction optimization of Acanthopanax senticosus polysaccharides and its antioxidant activity. Int. J. Biol. Macromol. 2013, 59, 290-294. [CrossRef] [PubMed]

31. Chen, C.; You, L.J.; Abbasi, A.M.; Fu, X.; Liu, R.H. Optimization for ultrasound extraction of polysaccharides from mulberry fruits with antioxidant and hyperglycemic activity in vitro. Carbohydr. Polym. 2015, 130, 122-132. [CrossRef] [PubMed]

32. Fu, L.; Chen, H.; Dong, P.; Zhang, X.; Zhang, M. Effects of ultrasonic treatment on the physicochemical properties and DPPH radical scavenging activity of polysaccharides from mushroom Inonotus obliquus. J. Food Sci. 2010, 75, C322-C327. [CrossRef] [PubMed]

33. Sahin, S.; Samli, R. Optimization of olive leaf extract obtained by ultrasound-assisted extraction with response surface methodology. Ultrason. Sonochem. 2013, 20, 595-602. [CrossRef] [PubMed]

34. Hou, F.; Wu, Y.; Kan, L.; Li, Q.; Xie, S.; Ouyang, J. Effects of Ultrasound on the Physicochemical Properties and Antioxidant Activities of Chestnut Polysaccharide. Int. J. Food Eng. 2016, 12, 439-449. [CrossRef]

35. Prakash Maran, J.; Manikandan, S.; Thirugnanasambandham, K.; Vigna Nivetha, C.; Dinesh, R. Box-Behnken design based statistical modeling for ultrasound-assisted extraction of corn silk polysaccharide. Carbohydr. Polym. 2013, 92, 604-611. [CrossRef] [PubMed]

36. Shen, X.; Fang, T.; Gao, F.; Guo, M. Effects of ultrasound treatment on physicochemical and emulsifying properties of whey proteins pre- and post-thermal aggregation. Food Hydrocoll. 2017, 63, 668-676. [CrossRef] 
37. Qiao, D.; Hu, B.; Gan, D.; Sun, Y.; Ye, H.; Zeng, X. Extraction optimized by using response surface methodology, purification and preliminary characterization of polysaccharides from Hyriopsis cumingii. Carbohydr. Polym. 2009, 76, 422-429. [CrossRef]

38. Zhao, C.; Li, X.; Miao, J.; Jing, S.; Li, X.; Huang, L.; Gao, W. The effect of different extraction techniques on property and bioactivity of polysaccharides from Dioscorea hemsleyi. Int. J. Biol. Macromol. 2017, 102, 847-856. [CrossRef] [PubMed]

39. Boulet, J.C.; Williams, P.; Doco, T. A Fourier transform infrared spectroscopy study of wine polysaccharides. Carbohydr. Polym. 2007, 69, 79-85. [CrossRef]

40. Jahanbin, K.; Abbasian, A.; Ahang, M. Isolation, purification and structural characterization of a new water-soluble polysaccharide from Eremurus stenophyllus (boiss. E buhse) baker roots. Carbohydr. Polym. 2017, 178, 386-393. [CrossRef] [PubMed]

41. Maran, J.P.; Priya, B. Ultrasound-assisted extraction of polysaccharide from Nephelium lappaceum L. fruit peel. Int. J. Biol. Macromol. 2014, 70, 530-536. [CrossRef] [PubMed]

42. Wang, Q.H.; Shu, Z.P.; Xu, B.Q.; Xing, N.; Jiao, W.J.; Yang, B.Y.; Kuang, H.X. Structural characterization and antioxidant activities of polysaccharides from Citrus aurantium L. Int. J. Biol. Macromol. 2014, 67, 112-123. [CrossRef] [PubMed]

43. Wu, W.; Zhu, Y.; Zhang, L.; Yang, R.; Zhou, Y. Extraction, preliminary structural characterization, and antioxidant activities of polysaccharides from Salvia miltiorrhiza Bunge. Carbohydr. Polym. 2012, 87, 1348-1353. [CrossRef]

44. Guo, X.; Shang, X.; Zhou, X.; Zhao, B.; Zhang, J. Ultrasound-assisted extraction of polysaccharides from Rhododendron aganniphum: Antioxidant activity and rheological properties. Ultrason. Sonochem. 2017, 38, 246-255. [CrossRef] [PubMed]

45. Tabarsa, M.; Anvari, M.; Joyner, H.S.; Behnam, S.; Tabarsa, A. Rheological behavior and antioxidant activity of a highly acidic gum from Althaea officinalis flower. Food Hydrocoll. 2017, 69, 432-439. [CrossRef]

46. Guo, X.; Ye, X.; Sun, Y.; Wu, D.; Wu, N.; Hu, Y.; Chen, S. Ultrasound effects on the degradation kinetics, structure, and antioxidant activity of sea cucumber fucoidan. J. Agric. Food. Chem. 2014, 62, 1088-1095. [CrossRef] [PubMed]

47. Zhang, L.; Ye, X.; Ding, T.; Sun, X.; Xu, Y.; Liu, D. Ultrasound effects on the degradation kinetics, structure and rheological properties of apple pectin. Ultrason. Sonochem. 2013, 20, 222-231. [CrossRef] [PubMed]

48. Zeng, H.; Zhang, Y.; Jian, Y.; Tian, Y.; Miao, S.; Zheng, B. Rheological properties, molecular distribution, and microstructure of Fortunella margarita (Lour.) swingle polysaccharides. J. Food Sci. 2015, 80, E742-E749. [CrossRef] [PubMed]

49. Shobha, M.S.; Tharanathan, R.N. Rheological behaviour of pullulanase-treated guar galactomannan on co-gelation with xanthan. Food Hydrocoll. 2009, 23, 749-754. [CrossRef]

50. Shen, X.; Zhao, C.; Guo, M. Effects of high intensity ultrasound on acid-induced gelation properties of whey protein gel. Ultrason. Sonochem. 2017, 39, 810-815. [CrossRef] [PubMed]

51. Dubois, M.; Gilles, K.A.; Hamilton, J.K.; Rebers, P.A.; Smith, F.J.A.C. Colorimetric method for determination of sugars and related substances. Anal. Chem. 1956, 28, 350-356. [CrossRef]

52. Sun, X.; Wang, C.; Wang, H.; Guo, M. Effects of Processing on Structure and Thermal Properties of Powdered Preterm Infant Formula. J. Food Sci. 2018, 83, 1685-1694. [CrossRef] [PubMed]

53. Wei, Y.; Lin, Y.; Xie, R.; Xu, Y.; Yao, J.; Zhang, J. The flow behavior, thixotropy and dynamical viscoelasticity of fenugreek gum. J. Food Eng. 2015, 166, 21-28. [CrossRef]

54. Zheng, J.; Zeng, R.; Kan, J.; Zhang, F. Effects of ultrasonic treatment on gel rheological properties and gel formation of high-methoxyl pectin. J. Food Eng. 2018, 231, 83-90. [CrossRef]

(C) 2019 by the authors. Licensee MDPI, Basel, Switzerland. This article is an open access article distributed under the terms and conditions of the Creative Commons Attribution (CC BY) license (http://creativecommons.org/licenses/by/4.0/). 